\title{
Urinary incontinence in climacteric afrodescendant women from the Colombian Caribbean
}

\author{
Alvaro Monterrosa-Castro ${ }^{1 *}$, Katheryn Portela-Buelvas ${ }^{2}$, Camil Castelo-Branco ${ }^{3}$
}

\begin{abstract}
${ }^{1}$ Department of Gynecology and Obstetrics, Women's Health Research Group, School of Medicine, University Cartagena, Colombia

${ }^{2}$ Department of Epidemiology, Women's Health Research Group, School of Medicine, University Cartagena, Colombia ${ }^{3}$ Department of Gynecology, Clinic Institute of Gynecology, Obstetrics and Neonatology, Faculty of MedicineUniversity of Barcelona, Hospital Clinic-Institute for Biomedical Research, August Pi i Sunyer (IDIBAPS), Barcelona, Spain
\end{abstract}

Received: 05 July 2019

Accepted: 13 September 2019

\section{*Correspondence:}

Dr. Alvaro Monterrosa-Castro,

E-mail: alvaromonterrosa@gmail.com

Copyright: () the author(s), publisher and licensee Medip Academy. This is an open-access article distributed under the terms of the Creative Commons Attribution Non-Commercial License, which permits unrestricted non-commercial use, distribution, and reproduction in any medium, provided the original work is properly cited.

\section{ABSTRACT}

Background: To assess the prevalence of urinary incontinence (UI) and to identify related factors in Afro-descendant Colombian women.

Methods: A cross-sectional study was carried out involving 40-59 year old women from the Colombian Caribbean. Socio-demographic characteristics were recorded and the International Consultation on Incontinence Questionnaire Short-Form (ICIQ-SF) and the 10-item cervantes scale were applied to identify UI and genitourinary symptoms, respectively.

Results: A cross-sectional study was carried out involving 40-59-year-old women from the Colombian Caribbean. Socio-demographic characteristics were recorded and the International Consultation on Incontinence Questionnaire Short-Form (ICIQ-SF) and the 10-item cervantes scale were applied to identify UI and genitourinary symptoms, respectively.

Conclusions: The prevalence of UI among climacteric afro-descendant women was close to 4\%. A history of PIH and PD consumption were related factors.

Keywords: African continental ancestry group, Afro-descendants, Climacteric, Ethnic group, Menopause, Urinary incontinence

\section{INTRODUCTION}

Urinary incontinence (UI) is a serious health problem in women. ${ }^{1}$ The International Urogynecological Association and the International Continence Society define UI as the discomfort produced by any involuntary loss of urine through the urethra. ${ }^{2,3}$ This condition is often under diagnosed because of health professionals seldom ask women about UI, and In turn, women do not discuss the complaint because of embarrassment or the perception that UI is a normal symptom of aging. ${ }^{1}$ Data from the Study of Women's Health Across the Nation (SWAN) suggests that belonging to an Afro-American ethnic group and the increase of age were conditions associated with a forty-eight and nine percent respectively, less probability of reporting UI. ${ }^{4}$

The same authors pointed out that women with greater severity of UI had a high probability of reporting this condition if the symptoms were daily, weekly or monthly, 
in comparison with those women who reported symptoms less than once a month. ${ }^{4}$ Urinary incontinence prevalence varies between $26-61 \% .^{1}$ Recent data suggest that among middle-aged women up to $45 \%$ experienced UI episodes a few times a month, while $15 \%$ referred this condition almost daily. ${ }^{4}$ Dieffeux reported that UI presence is higher in white women than in Afro-descendant or Asian women independently of other factors. ${ }^{5}$

Aging, obesity, being overweight, pelvic floor dysfunction, diabetes, history of vaginal delivery, gynecological surgeries, urinary infections, smoking, sedentary lifestyle, depression, and use of neuroactive drugs have been related to the presence of UI. ${ }^{6,7}$ Several scales have been proposed to identify UI, the most frequently used are: International Consultation on Incontinence Questionnaire Short Form (ICIQ-SF), Incontinence Quality of Life Questionnaire (IQOL), Overactive Bladder Questionnaire (OAB-q), and Incontinence Impact Questionnaire (IIQ). Some of these have been validated in various languages. ${ }^{5,8-11}$ Data on UI in climacteric Afro-descendant women in Latin America is limited and the lack of prevalence records is noteworthy. The aim of this study was to determine the prevalence of UI and its related factors in climacteric Afro-descendant women from the Colombian Caribbean.

\section{METHODS}

A cross-sectional study was carried out as a part of the CAVIMEC (Calidad de Vida en la Menopausia y Etnias Colombianas) project, approved by the ethics committee at Universidad de Cartagena, Colombia. This investigation supports the Collaborative Group for Research of the Climacteric in Latin America (REDLINC) and the OMEGA-II Women's Health Project.

The inclusion criteria were to be healthy women aged 4059 that recognize themselves as Afro-descendant, with typical phenotypic characteristics and born and raised in settlements of descendants of enslaved Africans brought to the Americas in the colonial era with little ethnic mixing and low socioeconomic condition. Participants included women from municipalities of Santa Ana, Barú and Ararca, all part of the insular area of Cartagena in the Colombian Caribbean. The study was conducted in 2018.

A group of trained female interviewers and health professionals belonging to the same communities recruited the participants in a door to door survey. They identified each woman and explained the scope of the research and the tools used. Exclusion criteria were women with physical or mental disorders who could not fill in the form, along with those who were illiterate, pregnant, being treated with chemotherapy or radiotherapy, and those who did not want to participate were excluded. Incorrectly filled in forms were not considered. A unique form was designed with different sections. In the first, participants were asked about socio- demographic characteristics. The second section included the ICIQ-SF and the 10-item Cervantes Scale. The ICIQSF was developed by Avery et al to assess the presence and severity of UI; this questionnaire consists of three items asking on the frequency and quantity of leaked urine and its impact on daily life over the last four weeks with Likert-type answers. ${ }^{8}$

The total score is obtained by adding all answers, with a maximum score of 21 . Klovning et al proposed that a score of 0 indicates absence of UI, and $\geq 1$ its presence. ${ }^{12}$ In addition, four categories of severity have been established: 1-5: mild, 6-12: moderate, 13-18: severe and 19-21: very severe. ${ }^{8}$ A fourth item not applied to the women studied here explores eight activities that provoke involuntary leaks according to the women's perception but these are not quantified using the scale. The 10 item cervantes scale is an adaptation of the 31-question version used to evaluate quality of life for menopausal women over the previous four weeks. ${ }^{13}$ The following items were taken from the abridged scale:

- I am afraid of making physical effort because of possible urine loss

- I feel vaginal itching due to excessive dryness.

These two statements were assessed by the participants with Likert-type options. Finally, the women's corporal weight was measured using a digital and calibrated weighing scale of Kenwell brand with a maximum capacity of $150 \mathrm{~kg}$. Height was measured using a stadiometer; waist circumference was measured at the level of the umbilicus, and the hip circumference at the level of the iliac crests with a flexible ruler while the woman was standing.

Nutritional status was established based on the classification of the body mass index (BMI) suggested by the World Health Organization. ${ }^{14}$ According to the ATPIII, abdominal obesity was established to be $>88 \mathrm{~cm}$ waist circumference1. ${ }^{15}$ Menopausal status was defined by application of the STRAW+10 staging system. ${ }^{16}$ The current intake of antidepressants, anxiolytics or antipsychotics was considered as use of psychoactive drugs (PD).

The last Colombian population census, carried out in 2005 , established that 4,347,590 women were aged 4059 ; $382,588(8.8 \%)$ belonged to black, mulato, AfroColombian or racial ethnic groups, denominated Afrodescendants in this study. Some $11.3 \%$ of that community lives in the Caribbean region, thus, 43,232 women were considered.

A sample size of 371 women was calculated with a $50 \%$ degree of heterogeneity, $5 \%$ error, and a confidence level of $95 \%$, a supplementary $10 \%$ was considered to compensate the refusals and another additional $10 \%$ to compensate for incorrectly fulfilled forms. Therefore, the initial survey included 448 women. 


\section{Statistical analysis}

The EPI-INFO 7.2.2.6 statistical program (Centers for Disease Control and Prevention, Atlanta, USA, 2018) was used to analyze the data. The Kolmogorov-Smirnov test was used to assess the normality of the sample. The continuous data was presented in median with interquartile range; categorical data was expressed in absolute numbers and percentages with 95\%CI. Differences between women with and without UI were assessed with ANOVA or Student's t-test and MannWhitney or Kruskal-Wallis tests.

The Bartlett test was used to evaluate the homogeneity of measured variance. Categorical variables were evaluated with $\chi^{2}$ or Fisher tests. An unadjusted logistic regression (OR) and adjusted logistic regression (aOR) with 95\% CI were carried out with UI as dependent variable; the sociodemographic characteristics as well as the two questions of the 10-item Cervantes Scale were used as independent variables. A Spearman correlation coefficient (rho) was estimated between socio-demographic quantitative variables and punctuations of ICIQ-SF. A $p$ value of $<0.05$ was considered to be statistically significant.

Participants were voluntary and anonymous and gave their previous informed consent according to the Declaration of Helsinki. Biological samples were not taken. The scientific, technical and administrative rules for health research, established in the Resolution 008430 of 1993 by the Ministry of Health and Social Protection of Colombia were adhered to, and the present study is free of risks. Participants could stop filling out the form when they wanted to. All the incomplete documents were destroyed.

\section{RESULTS}

Of the initial sample, $9(2.0 \%)$ women refused to participate and $69(15.4 \%)$ forms were incorrectly completed; therefore, $370(82.6 \%)$ women were finally included in the study.

The women's average age and BMI was 49.0 (10.0) years and $27.2(8.5) \mathrm{kg} / \mathrm{m}$ respectively, $12.7 \%$ had arterial hypertension $(\mathrm{AH}) ; 6,2 \%$ had diabetes mellitus, $34.6 \%$ had previously undergone hysterectomy and $49.5 \%$ were in the postmenopausal stage; $14(3.8 \%)$ women had UI according to the ICIQ-SF. Comparing women with and without UI, differences were observed only when subjects took in PD, had a current partner, history of pregnancy-induced hypertension (PIH) and current $\mathrm{AH}$ (Table 1).

Among the 14 women with UI complaints, two of each three reported loss of urine around once a week or less. Half of them manifested to be afraid of making physical effort because of possible urine loss or feeling vaginal itching due to excessive dryness (Table 2). ICIQ-SF identified three grades of UI: mild: $50.0 \%$ (95\% CI: $23.0-$ 76.9), moderate: $42.8 \%$ (95\% CI: 17.6 - 71.1) and severe: $7.1 \%$ (95\% CI: 0.2-33.9). None of the women presented very severe UI. Cronbach's alpha was estimated to be 0.791 .

A binary logistic regression model was used to establish factors associated with UI (Table 3). The used PD and history PIH were significantly associated with UI OR: 15.09 (95\% CI:1.62-140.27) and OR: 7.07 (95\% CI: 1.58-31.53) respectively. A significant statistical association was not observed between the number of daily cups of coffee and UI. There was no significant correlation among age, education, weight, height, BMI, and number of sexual encounters per week with UI, $\mathrm{p}>0.05$.

\section{DISCUSSION}

In Latin America and the Caribbean, the Afro-descendant population is constituted of individuals from black ethnic groups. The term "African-American" usually tends to be assigned to the black population residing in North America. In 2015, it was indicated that $21 \%$ of the total population of Latin America was Afro-descendant, with Brazil and Cuba having the highest proportion among its population (35-55\%), followed by Ecuador, Panama, Costa Rica and Colombia, which have $7-11 \%$ of Afrodescendant communities, according to the Economic Commission for Latin America and the Caribbean (CEPAL). ${ }^{17}$

Several countries have been passing laws to protect and respect the Afro-descendant population. The year 2011 was declared "International Year for People of African descent" by the United Nations; also, the period 20152024 was named the "International Decade for People of African Descent". ${ }^{17}$ The CAVIMEC research project, that supports the present study, has reported several situations that affect the health and quality of life conditions of climacteric Afro-Colombian women. ${ }^{18-20}$

The UI prevalence observed in non-hospitalized Afrodescendant women in this study was close to $4 \%$. This figure is much lower than the $24 \%$ reported by Rebassa et al among Spanish women using the same questionnaire. ${ }^{21}$

In other studies, in Russia, the Czech Republic and Turkey, numbers were even higher: one in four women aged between 40-59 years, all of them contacted in their place of residence, manifested some type of UI and it was still higher in those who were over 60 years old. ${ }^{22}$

In Norway, the researchers found that $27-30 \%$ of the 50-59 age group reported an increase in UI over the previous few years. ${ }^{23}$ Finally, Cárdenas et al found that in USA the prevalence of UI was of $48 \%$ in postmenopausal women and $30 \%$ in premenopausal women. ${ }^{24}$ 
Table 1: Socio - demographic characteristics.

\begin{tabular}{|c|c|c|c|c|c|}
\hline \multirow[t]{2}{*}{ Variable } & & $\begin{array}{l}\text { Total } \\
\mathbf{N}=\mathbf{3 7 0}\end{array}$ & $\begin{array}{l}\text { With urinary } \\
\text { incontinence } \\
14(3.8 \%)\end{array}$ & $\begin{array}{l}\text { Without urinary } \\
\text { incontinence } \\
356(96.2 \%)\end{array}$ & \multirow[t]{2}{*}{ p } \\
\hline & & \multicolumn{3}{|c|}{ Median (rank) } & \\
\hline \multicolumn{2}{|l|}{ Age, years } & $49.0(10.0)$ & $48.5(10.0)$ & $49.0(10.0)$ & 0.86 \\
\hline \multicolumn{2}{|l|}{ Education years } & $5.0(6.0)$ & $5.0(4.0)$ & $5.0(6.0)$ & 0.35 \\
\hline \multicolumn{2}{|l|}{ Children } & $4.0(2.0)$ & $5.0(4.0)$ & $4.0(2.0)$ & 0.05 \\
\hline \multicolumn{2}{|l|}{ Coitus per week } & $1.0(3.5)$ & $1.0(3.0)$ & $1.0(3.5)$ & 0.26 \\
\hline \multicolumn{2}{|l|}{ Body Mass Index kg/m² } & $27.2(8.5)$ & $31.0(12.4)$ & $27.1(8.4)$ & 0.34 \\
\hline \multicolumn{2}{|l|}{ Waist-hip ratio $\mathrm{cm}$} & $0.91(0.07)$ & $0.88(0.06)$ & $0.91(0.06)$ & 0.52 \\
\hline & $92.0(16.0)$ & $90.0(12.0)$ & $92.0(16.0)$ & 0.20 \\
\hline \multicolumn{2}{|l|}{ Waist circumference $\mathrm{cm}$} & $\mathrm{n}(\%)$ & & & \\
\hline \multirow{2}{*}{ Age range years } & $40-49$ & $204(55.2)$ & $7(50.0)$ & $197(55.3)$ & \multirow{2}{*}{0.69} \\
\hline & $50-59$ & $166(44.8)$ & $7(50.0)$ & $159(44.7)$ & \\
\hline \multirow{2}{*}{ Level of education years } & Less than 11 & $353(95.4)$ & $12(85.7)$ & $341(95.8)$ & \multirow{2}{*}{0.07} \\
\hline & High or equal to 11 & $17(4.6)$ & $2(14.3)$ & $15(4.2)$ & \\
\hline \multirow{4}{*}{ Rank of children } & 0 & $2(0.5)$ & 0 & $2(0.5)$ & \multirow{4}{*}{0.24} \\
\hline & 1 and 2 & $81(21.9)$ & $2(14.3)$ & $79(22.2)$ & \\
\hline & 3 and 4 & $168(45.4)$ & $4(28.6)$ & $164(46.1)$ & \\
\hline & 5 and more & $119(32.2)$ & $8(57.1)$ & $111(31.2)$ & \\
\hline \multirow{5}{*}{ Marital status } & Married & $83(22.4)$ & $1(7.1)$ & $82(23.0)$ & \multirow{5}{*}{0.06} \\
\hline & Civil union & $218(58.9)$ & $7(50.00)$ & $211(59.3)$ & \\
\hline & Divorced & $37(10.0)$ & $2(14.3)$ & $35(9.8)$ & \\
\hline & Single & $15(4.0)$ & $2(14.3)$ & $13(3.7)$ & \\
\hline & Widowed & $17(4.6)$ & $2(14.3)$ & $15(4.2)$ & \\
\hline Current partner & Yes & $298(89.5)$ & $8(57.1)$ & $290(81.5)$ & 0.02 \\
\hline \multirow{4}{*}{ Nutritional status } & Underweight & $15(4.0)$ & $1(7.1)$ & $14(3.9)$ & \multirow{4}{*}{0.13} \\
\hline & Normal weight & $108(29.2)$ & $4(28.7)$ & $104(29.2)$ & \\
\hline & Overweight & $121(32.7)$ & $1(7.1)$ & $120(33.7)$ & \\
\hline & Obesity & $126(34.1)$ & $8(57.1)$ & $118(33.2)$ & \\
\hline Abdominal obesity & Yes & $249(67.3)$ & $8(57.1)$ & $241(67.7)$ & 0.40 \\
\hline Sedentary behavior & Yes & $13(3.5)$ & $1(7.1)$ & $12(3.3)$ & 0.45 \\
\hline Use of oral contraceptives & Yes & $19(5.1)$ & $1(7.1)$ & $18(5.1)$ & 0.72 \\
\hline Estrogen replacement therapy & Yes & $72(19.5)$ & 0 & $72(20.3)$ & 0.06 \\
\hline Use of psychotropic drugs & Yes & $13(3.5)$ & $3(21.4)$ & $10(2.8)$ & 0.00 \\
\hline Use of phytoestrogens & Yes & $40(10.8)$ & 0 & $40(11.24)$ & 0.18 \\
\hline Current smoking & Yes & $48(13.0)$ & $2(14.3)$ & $46(13.0)$ & 0.88 \\
\hline Alcohol consumption & Yes & 43 (11.6) & $3(21.4)$ & 40 (11.9) & 0.24 \\
\hline Coffee consumption & Yes & $252(68.2)$ & $7(50.0)$ & $245(68.8)$ & 0.13 \\
\hline Church attendance & Yes & $275(74.3)$ & $10(71.4)$ & $265(74.4)$ & 0.80 \\
\hline Arterial hypertension & Yes & $47(12.7)$ & $7(50.0)$ & $40(11.3)$ & 0.00 \\
\hline $\begin{array}{l}\text { Arterial hypertension in } \\
\text { pregnancy }\end{array}$ & Yes & $99(26.7)$ & $8(57.2)$ & $91(25.6)$ & 0.00 \\
\hline Diabetes mellitus & Yes & $23(6.2)$ & $2(14.3)$ & $21(5.9)$ & 0.20 \\
\hline Bilateral oophorectomy & Yes & $46(12.4)$ & $1(7.1)$ & $45(12.6)$ & 0.54 \\
\hline Menopausal status & $\begin{array}{l}\text { Pre/peri-menopause } \\
\text { Postmenopause }\end{array}$ & $\begin{array}{l}187(50.6) \\
183(49.4)\end{array}$ & $\begin{array}{l}6(42.9) \\
8(57.1)\end{array}$ & $\begin{array}{l}181(50.8) \\
175(49.2)\end{array}$ & 0.55 \\
\hline Previously hysterectomized & Yes & $128(34.6)$ & $4(28.6)$ & $124(34.8)$ & 0.62 \\
\hline $\begin{array}{l}\text { Uterine resection before } \\
\text { menstruation }\end{array}$ & Yes & 49 (13.3) & $1(7.1)$ & 48 (13.5) & 0.49 \\
\hline
\end{tabular}


Table 2: Perception of genitourinary symptoms in women with urinary incontinence.

\begin{tabular}{|c|c|c|}
\hline \multicolumn{2}{|c|}{$\begin{array}{l}\text { International consultation on incontinence questionnaire-short form } \\
\text { ICIQ-SF }\end{array}$} & n $(\%)(95 \% \mathrm{CI})$ \\
\hline \multirow{6}{*}{ How often do you leak urine? } & Never & $1(7.1)(0.18-33.87)$ \\
\hline & About once a week or less often & $9(64.3)(35.14-87.24)$ \\
\hline & Two or three times a week & $1(7.1)(0.18-33.87)$ \\
\hline & About once a day & $1(7.1)(0.18-33.87)$ \\
\hline & Several times a day & $2(14.3)(1.78-42.81)$ \\
\hline & All the time & $1(7.1)(0.18-33.87)$ \\
\hline \multirow{4}{*}{ How much urine do you usually leak? } & None & $3(21.5)(4.66-50.84)$ \\
\hline & A small amount & $9(64.3)(35.14-87.24)$ \\
\hline & A moderate amount & $1(7.1)(0.18-33.87)$ \\
\hline & A large amount & $1(7.1)(0.18-33.87)$ \\
\hline \multirow{6}{*}{$\begin{array}{l}\text { How much does leaking urine interfere with your } \\
\text { everyday life? }\end{array}$} & 0 (Not at all) & $4(28.6)(8.39-58.10)$ \\
\hline & $1-2$ & $5(35.7)(12.76-64.86)$ \\
\hline & 3 & $2(14.3)(1.78-42.81)$ \\
\hline & 4 & $2(14.3)(1.78-42.81)$ \\
\hline & $5-6-7-8-9$ & $1(7.1)(0.18-33.87)$ \\
\hline & 10 (A great deal) & 0 \\
\hline Cervantes short form scale $\mathbf{- 1 0}$ & & $\mathrm{n}(\%)(95 \% \mathrm{CI})$ \\
\hline \multirow{5}{*}{$\begin{array}{l}\text { I am afraid of performing physical efforts because } \\
\text { my urine leaks }\end{array}$} & Never & $7(50.0)(24.04-76.96)$ \\
\hline & Seldom & $7(50.0)(24.04-76.96)$ \\
\hline & Sometimes & 0 \\
\hline & Almost always & 0 \\
\hline & All the time & 0 \\
\hline \multirow{5}{*}{ I have vaginal discomfort and dryness } & Never & $7(50.0)(24.04-76.96)$ \\
\hline & Seldom & $6(42.9)(17.66-71.14)$ \\
\hline & Sometimes & 0 \\
\hline & Almost always & $1(7.1)(0.18-33.87)$ \\
\hline & All the time & 0 \\
\hline
\end{tabular}

Table 3: Factors associated with urinary incontinence.

\begin{tabular}{|lllll|}
\hline Variable & OR $(95 \%$ CI $)$ & P & aOR $(95 \%$ CI $)$ & P \\
\hline Use of psychotropic drugs & $9.43(2.27-39.15)$ & 0.009 & $15.09(1.62-140.27)$ & 0.01 \\
\hline Current partner & $0.30(0.10-0.90)$ & 0.03 & $0.35(0.08-1.46)$ & 0.15 \\
\hline Arterial hypertension & $7.90(2.63-23.68)$ & $<0.001$ & $3.64(0.86-15.35)$ & 0.07 \\
\hline History of arterial hypertension in pregnancy & $3.88(1.31-11.49)$ & 0.01 & $7.07(1.58-31.53)$ & 0.01 \\
\hline Current smoking & $1.12(0.24-5.18)$ & 0.70 & $1.19(0.17-8.02)$ & 0.85 \\
\hline Alcohol consumption & $2.15(0.57-8.05)$ & 0.21 & $1.11(0.15-7.91)$ & 0.91 \\
\hline Coffee consumption & $0.45(0.15-1.32)$ & 0.15 & $0.67(0.17-2.58)$ & 0.56 \\
\hline Use of oral contraceptives & $1.44(0.17-11.66)$ & 0.52 & $1.55(0.11-20.69)$ & 0.73 \\
\hline Sedentary behavior & $2.20(0.26-18.25)$ & 0.39 & $7.26(0.59-88.30)$ & 0.11 \\
\hline Church attendance & $0.85(0.26-2.80)$ & 0.76 & $1.12(0.22-5.58)$ & 0.88 \\
\hline Diabetes mellitus & $2.65(0.55-12.65)$ & 0.21 & $1.68(0.26-10.57)$ & 0.57 \\
\hline Abdominal obesity & $0.63(0.21-1.87)$ & 0.39 & $0.77(0.19-3.09)$ & 0.72 \\
\hline Previously hysterectomized & $0.74(0.23-2.43)$ & 0.77 & $0.21(0.04-1.10)$ & 0.06 \\
\hline Bilateral oophorectomy & $0.53(0.06-4.16)$ & 1.00 & $0.58(0.05-6.61)$ & 0.66 \\
\hline $\begin{array}{l}\text { I am afraid of performing physical efforts } \\
\text { because my urine leaks }\end{array}$ & $0.69(0.23-2.03)$ & 0.59 & $0.27(0.02-2.86)$ & 0.28 \\
\hline I have vaginal discomfort and dryness & $2.78(0.95-8.15)$ & 0.06 & $7.07(0.73-67.82)$ & 0.08 \\
\hline
\end{tabular}

Data on UI in women and race are contradictory. Leroy et al in a systematic review of the literature suggested that the presence of UI was higher in white and Hispanic (17$41 \%$ ) than it is in black and Asian (9-26\%) women. ${ }^{25}$ 
They also found differences in the type of UI, which could be explained by the exposure to factors such as urethral closure pressure, urinary tract infections, being overweight, obesity, constipation, diabetes mellitus type 2, chronic obstructive pulmonary disease, and symptoms of depression. Studies on UI involving Latin American indigenous women and those involving Afro-descendant women are scant. Monterrosa et al identified a high prevalence of urogenital disorders including vaginal dryness and bladder and sexual function disturbances in Colombian indigenous postmenopausal women. ${ }^{26}$ Severe UI was detected in one of each two women of this population. Furthermore, Arteta et al found a high prevalence of severe bladder dysfunctions among indigenous women aged 40-59 from the Colombian Caribbean. ${ }^{27}$

In the present study, $57.1 \%$ of the participants with UI were postmenopausal. Six out of ten women were overweight/obese or with abdominal obesity and half of them had a sexual partner. This figure is two folds those observed by Juliato et al who reported a $23.6 \%$ of UI among Brazilian women aged 52.5 $\pm 4.4 .^{28}$ Two thirds of these women were in postmenopause, one third was overweight, half were obese, $80.2 \%$ had abdominal obesity, and $77.4 \%$ had a sexual partner. In this regard, Çayan et al in a study involving 1217 sexually active women from Turkey showed a UI prevalence of $14.6 \%$. In this study, UI complaints were more common among women of advanced age, high BMI, low educational level, and older sexual partners. ${ }^{10}$

Cagnacci et al showed that $35.6 \%$ of postmenopausal Italian women reported UI. ${ }^{6}$ In Spain, $25.2 \%$ of women expressed moderate/severe UI, $34.8 \%$ experienced loss of urine once a week and $75.6 \%$ reported minimal escapes of urine. ${ }^{21}$ In contrast, in present sample, half of the women with UI expressed it as moderate to severe; two out three women reported loss of urine once a week and a similar amount presented a minimal loss of urine. In another study, involving mestizo population, from a geographic area of ancestral indigenous American settlement, it was found severe/very severe UI in $28.4 \%$ of women and vaginal dryness in the $64.4 \% .^{29}$ Studies that explain the association between severity of UI and ethnic group were not found.

It should be noted that it is difficult to identify the factors related to UI. Biopsychosocial determinants and medical and surgical history have been assessed by different authors. ${ }^{5,7,28}$ In the present study, the used of PD OR: 9.43 (95\% CI: 2.27-39.15), history of PIH OR: 3.88 (95\% CI: 1.31-11.49) and having AH OR: 7.90 (95 CI\%: 2.6323.68) were associated with a greater presence of UI, whereas having sexual partner was a protective factor OR: 0.30 (95 CI\%: 0.10-0.90). This applies only when the estimations were not adjusted or when the adjustments were carried out with the different considered variables. Only the used of PD and history of PIH continued to be factors associated with UI.
Townsend et al found UI prevalence of $14 \%$ using a different questionnaire from the ICIQ-SF in Mexican postmenopausal women, $60 \%$ of them aged 50-59, older than those observed in the study, which included women in all menopausal stages. ${ }^{30}$ In addition, the researchers found the following factors to be associated with UI: having four or more children aOR: 1.43 (95\% CI: 1.04-1.96), using hormonal therapy aOR :1.26 (95\% CI: 1.14-1.39), and being a current smoker aOR : 1.23 (95\% CI: 1.09-1.39). However, statistically significant correlations for nutritional status, diabetes or arterial hypertension were not found. On the other hand, Cagnacci et al showed that $35.6 \%$ of postmenopausal women, with an average age of 55.8 \pm 5.8 years, reported UI by means of tools different from ICIQ-SF in an Italian university hospital. ${ }^{6}$ Then, when a logistic regression model was applied, the only associated factor was bladder prolapse OR: 3.72 (95\% CI: 2.59-5.34), $\mathrm{p}=0.001$.

Urinary incontinence is a component of geriatric syndrome, which is defined as a multifactorial health status that increases as multisystemic disorders are accumulated, making people more vulnerable in the face of challenging situations with the consequent deterioration of quality of life and disability. ${ }^{31}$ This condition must be considered in a comprehensive way since it is a syndrome with a high burden of disease for the patients and their families.

Ranges of prevalence of UI are broad with important differences among the studies without noteworthy biological explanations. ${ }^{1}$ However, several reasons must be considered. First, a diversity of tools and resources were applied to obtain information. Second, the decisions made to interpret UI as a symptom or disease by women and health professionals are highly subjective. ${ }^{1,3,25}$ The diversity of prevalence makes it necessary to study the data of each community in order to establish early actions for primary care that involve efficient treatment and avoidance of the deterioration of women's quality of life.

Health professionals should ask about UI to climacteric women. The menopausal transition implies anatomical and physiological changes due to estrogen deficiency and aging. It has been pointed out that the reduction of elastin and blood flow, proliferation of connective tissue, vaginal epithelium slimming, changes in the vaginal maturation index, glycogen decrease in vaginal epithelial cells, changes in the facultative vaginal flora, and vaginal $\mathrm{pH}$ increase are normal symptoms in this stage. Due to the aforementioned symptoms, women usually present urogenital and vulvovaginal signs that, nowadays, are grouped under the term genitourinary syndrome of menopause. ${ }^{32,33}$

In spite of the low prevalence detected in this study the need to look for early manifestations is mandatory. Clinical records should include the amount and frequency of spontaneous urine leaked, nocturia, urge, and the impact of this complaints since all of them have a 
negative impact on quality of life and could involve the deterioration of state of mind, depression, anxiety, low self-esteem, embarrassment, and social isolation. ${ }^{1,10,23,30}$

This study is mainly limited by its cross-sectional design and by the lack of more objective measures such as urodynamics, Q-tip test or ultrasounds. The survey did not ask the participants if they had been previously diagnosed with UI, had felt embarrassment because of these manifestations, or if they had presented alterations of the pelvic floor. Other limitations include the lack of data on obstetric history, gynecological vaginal surgeries, urinary infections and types of UI.

On the other hand, this study is one of the first carried out in a healthy Afro-descendant population in Latin America, in which the participants were interviewed outside health centers as an initial approach to UI in the region. However, the results could not necessarily be extrapolated to other communities. Finally, more studies involving other Afro-descendant populations are needed in order to establish a real estimation of the statistical weight of the associated factors. Sufficient comparative studies that examine ethnic group do not exist to identify the race value as a variable in UI prevalence. The application of different tools to explore UI is limited to comparisons among the obtained information. Although it is true that UI is considered to be a geriatric syndrome, this disorder is present in middle-aged women, and so the topic requires more basic and clinical studies to develop prevention and intervention actions. In conclusion: almost $4 \%$ of climacteric Afro-descendant women in the Colombian Caribbean, assessed presented UI. The main related factors were the use of psychotropic drugs and a history of pregnancy-induced hypertension.

\section{CONCLUSION}

The prevalence of UI among climacteric afro-descendant women was close to $4 \%$. A history of PIH and PD consumption were related factors.

\section{ACKNOWLEDGMENTS}

Authors would like to thank Teresa Beltran Barrios, medical students of the Universidad de Cartagena who are part of the Grupo de Investigación Salud de la Mujer for their support during study.

Funding: The CAVIMEC project (Calidad de Vida en la Menopausia y Etnias Colombianas) is supported by Universidad de Cartagena, Colombia, as a part of the plans for the consolidation of research groups categorized by COLCIENCIAS. Memorandum of association $N^{\circ}$ 126-2017 of resolution $N^{\circ}$ 00961-2017 and memorandum of association $N^{\circ}$ 040-2017 of resolution $N^{\circ}$ 02482-2016. None of the authors receive fees for their participation.

Conflict of interest: None declared
Ethical approval: The study was approved by the Institutional Ethics Committee

\section{REFERENCES}

1. Milsom I, Gyhagen M. The prevalence of urinary incontinence. Climacteric. 2018;21:1-6.

2. Haylen BT, Ridder D, Freeman RM. An international urogynecological association/ international continence society joint report on the terminology for female pelvic floor dysfunction. Int Urogynecol J. 2010;21(1):5-26.

3. Abrams P, Cardozo L, Fall M. The standardisation of terminology in lower urinary tract function: report from the standardisation sub-committee of the International Continence Society. Urology. 2003;61(1):37-49.

4. Waetjen LE, Xing G, Johnson WO. Factors associated with reasons incontinent midlife women report for not seeking urinary incontinence treatment over 9 years across the menopausal transition. Menopause. 2018;25(1):29-37.

5. Deffieux X, Thubert T, Demoulin G. Incontinencia urinaria de la mujer. EMC Ginecol. 2016:52(1):1-16.

6. Cagnacci A, Palma F, Carbone MM. Association between urinary incontinence and climacteric symptoms in postmenopausal women. Menopause. 2017;24(1):77-84.

7. Mitchell ES, Woods NF. Correlates of urinary incontinence during the menopausal transition and early postmenopause: observations from the seattle midlife women's health study. Climacteric. 2013;16(6):653-62.

8. Avery K, Donovan J, Peters TJ. ICIQ: a brief and robust measure for evaluating the symptoms and impact of urinary incontinence. Neurourol Urodyn. 2004;23(4):322-30.

9. Güvenç G, Kocaöz S, Kök G. Quality of life in climacteric Turkish women with urinary incontinence. Int J Nurs Pract. 2016;22(6):649-59.

10. Çayan S, Yaman Ö, Orhan İ. Prevalence of sexual dysfunction and urinary incontinence and associated risk factors in Turkish women. Eur J Obstet Gynecol Reprod Biol. 2016;203:303-8.

11. Thüroff JW, Abrams $P$, Andersson KE. EAU guidelines on urinary incontinence. Eur Urol.2011;59(3):387-400.

12. Klovning A, Avery K, Sandvik H. Comparison of two questionnaires for assessing the severity of urinary incontinence: the iciq-ui sf versus the incontinence severity index. Neurourol Urodyn. 2009;28(5):411-5.

13. López PFR, Alonso FAM, Roncero PG, Chedraui P, Castro MÁ, Llaneza P. Assessment of menopauserelated symptoms in mid-aged women with the 10 item Cervantes Scale. Maturitas. 2013;76(2):151-4.

14. World Health Organization. Physical status: the use and interpretation of anthropometry. 1995. Technical Report Series no: 854. Geneva: WHO. 
15. Lean ME, Han TS, Morrison CE. Waist circumference as a measure for indicating need for weight management. Br Med J. 1995;311:158-61.

16. Harlow SD, Gass M, Hall JE, et al. Executive summary of the Stages of Reproductive Aging Workshop + 10: addressing the unfinished agenda of staging reproductive aging. J Clin Endocrinol Metab. 2012;97(4):1159-68.

17. Unidas N, Cepal, Ops, Unfpa. Situación de las personas afrodescendientes en América Latina y desafíos de políticas para la garantía de sus derechos. Publicación de las Naciones Unidas. 2017. Impreso en Naciones Unidas, Santiago. Available at: https://www.cepal.org/es/publicaciones/42654-

situacion-personas-afrodescendientes-america-latinadesafios-politicas-la Accessed 24 December 2018.

18. Fernanda Mercado-Lara M, Monterrosa-Castro A, Carolina Duran-Mendez L. Assessment of quality of life of climacteric women using the Cervantes scale. Influence of ethnicity. Revista Peruana De Ginecologia Y. Obstetricia. 2018 Jan 1;64(1):13-25.

19. Monterrosa-Castro Á, Márquez-Vega J, ArtetaAcosta C. Sexual dysfunction in climacteric women of African descent from the Colombian Caribbean region. Iatreia. 2014;27(1):31-41.

20. Monterrosa-Castro Á, Durán-Méndez LC, SalguedoMadrid M. Menopausal manifestations and quality of life in afro-Colombians valuation whit Cervantes scale. Iatreia. 2017;30(4):376-90.

21. Rebassa M, Taltavull JM, Gutiérrez C. Urinary Incontinence in Mallorcan Women: prevalence and quality of life. actas urológicas españolas (English Edition). 2013;37(6):354-61.

22. Kogan MI, Zachoval R, Ozyurt C. Epidemiology and impact of urinary incontinence, overactive bladder, and other lower urinary tract symptoms: results of the EPIC survey in Russia, Czech Republic, and Turkey. Curr Med Res Opin. 2014;30(10):2119-30.

23. Shlain I, Lavy Y, Arbel R. Urinary incontinence type, symptoms, and quality of life: a comparison between grand multipara and non-grand multipara women aged $\geq 50$ years. Jpn J Nurs Sci. 2018;15(4):309-17.

24. Cardenas-Trowers OO, Borgstrom M, Addis I. Associations between type and route of hormone use on urinary incontinence and pelvic organ prolapse in premenopausal and postmenopausal women. Female Pelvic Med Reconstr Surg. 2018;24(2):100-4.
25. Leroy LS, Lopes MHBM, Shimo AKK. Urinary incontinence in women and racial aspects: a literature review text context nursing, Florianópolis. 2012;21(3):692-701.

26. Monterrosa-Castro ÁD, Paternina-Caicedo Á, Márquez-Vega J, Romero-Pérez I. Prevalence of urogenital symptoms among Colombian indigenous postmenopausal women. Iatreia. 2012 Dec; 25 (4): 357-68.

27. Arteta-Acosta C, Márquez-Vega J, MonterrosaCastro Á. Severe bladder problems: main menopausal symptoms among zenues colombian indigenous women. Revista Salud Uninorte. 2012 Dec;28(2):283-97.

28. Juliato CR, Baccaro LF, Pedro AO. Factors associated with urinary incontinence in middle-aged women: a population-based household survey. Int Urogynecol J. 2017;28(3):423-9.

29. Monterrosa-Castro A, Márquez-Vega J, ArtetaAcosta C. Quality of life and sexual dysfunction in climacteric women from a Colombian Caribbean region. Revcienc Biomed. 2014;5(1):55-65.

30. Townsend MK, Lajous M, Campos RH. Risk factors for urinary incontinence among postmenopausal Mexican women. Int Urogynecol J. 2017;28(5):76976.

31. Sohn K, Lee CK, Shin J, Lee J. Association between female urinary incontinence and geriatric health problems: results from Korean longitudinal study of ageing (2006). Korean J Fam Med. 2018;39(1):10-4.

32. Portman DJ, Gass ML. Vulvovaginal atrophy terminology consensus conference panel (2014). genitourinary syndrome of menopause: new terminology for vulvovaginal atrophy from the International society for the study of women's sexual health and the North American menopause society. Menopause. 2014;21(10):1063-8.

33. Moral E, Delgado JL, Carmona F. Genitourinary syndrome of menopause prevalence and quality of life in Spanish postmenopausal women. The GENISSE study. Climacteric. 2018;21(2):167-73.

Cite this article as: Monterrosa-Castro A, PortelaBuelvas K, Castelo-Branco C. Urinary incontinence in climacteric afrodescendant women from the Colombian Caribbean. Int J Reprod Contracept Obstet Gynecol 2019;8:3817-24. 